\title{
PELATIHAN PENGOLAHAN KUNYIT MENJADI SERBUK MINUMAN SIAP SEDUH UNTUK MENINGKATKAN KREATIVITAS DAN EKONOMI MASYARAKAT DUSUN GEMBES DESA SLAHUNG KECAMATAN SLAHUNG
}

\author{
Zeni Murtafiati Mizani \\ IAIN Ponorogo \\ zeni@iainponorogo.ac.id
}

\begin{abstract}
ABSTRAK
Kegiatan pengabdian masyarakat ini bertujuan untuk meningkatkan pengetahuan, kreativitas dan keterampilan masyarakat Dusun Gembes, Desa Slabung Kec. Slahung, Kabupaten Ponorogo untuk mengolah kunyit menjadi menjadi minuman siap seduh. Kegiatan dilaksanakan dua kali bertempat di rumah Bapak Kasun dan di rumah Bapak Kepala Desa dengan melibatkan 20 orang pada tahap pertama, dan 40 orang pada tahap kedua. Pada kegiatan ini digunakan metode penyuluhan interaktif dan demonstrasi dengan melalui tiga tabap, yakni tahap persiapan, pelaksanaan dan evaluasi. Hasil pelaksanaan kegiatan menunjukean terjadinya peningkatan pengetabuan sasaran tentang kunyit serta pengolabannya menjadi minuman siap seduh. Sasaran juga tertarik untuk mengonsumsi dan memproduksi sendiri minuman rempab yang didemonstrasikan, dan akan mempraktekekan penjualan bubuk kunyit siap sedub untuk meningkatkan taraf ekonomi masyarakat. Masyarakat juga antusias untuk menyampaikan pengetahuan yang diperoleh kepada orang lain di Dusun Gembes.
\end{abstract}

Kata Kunci: Pelatihan, Serbuk Kunyit, Ekonomi Masyarakat

\begin{abstract}
This community service activity aims to increase the knowledge, creativity and skills of the people of Gembes Hamlet, Slahung Village, Kec. Slahung, Ponorogo Regency to process turmeric into a ready-brewed drink. The activity was carried out twice at the house of Mr. Kasun and at the house of the Village Head, involving 20 people in the first stage, and 40 people in the second stage. In this activity, interactive counseling and demonstration methods are used through three stages, namely the preparation, implementation and evaluation stages. The results of the implementation of the activity showed an increase in target knowledge about turmeric and its processing into a brewed drink. are also interested in consuming and producing their own spice drinks which are demonstrated, and will practice selling turmeric powder ready to brew to improve the economic level of the community. The Gembes Village community is also enthusiastic about passing on their knowledge to others.
\end{abstract}

Keywords: Training, Turmeric Powder, Community Economy

\section{PENDAHULUAN}

Indonesia merupakan nergara yang mempunyai keanekaragaman hayati dengan berbagai jenis tanaman. Diantara berbagai jenis tanaman tersebut 2.500 jenis tanaman adalah tanaman obat-obatan. Dengan keanekaragaman hayati ini, 


\section{Indonesian Engagement Journal}

Vol. 2 No. 1 Juni 2021

masyarakat Indonesia secara turun temurun mewariskan resep minum-minuman dan obat-obatan tradisional secara turun temurun yang memiliki khasiat tertentu bagi kesehatan. Di antara keanekaragaman hayati yang biasa dimanfaatkan untuk minuman dan obat-obatan adalah kunyit. Kunyit merupakan tanaman suku temutemuan (Zingiberaceae). Kunyit biasa ditanam di kebun pekarangan rumah, dan di daerah hutan jati. Kunyit memiliki banyak manfaat sebagai jamu dan minuman herbal karena tinggi kandungan senyawa atau komponen fungsional pada kunyit, seperti minyak astiri dan kurkuminoid. ${ }^{1}$ Kurkuminoid adalah senyawa yang berpotensi sebagai antioksidan, ${ }^{2}$ senyawa hipokolesteromik, kolagogum, koleretik, bakteriostatik, spasmolitik, anti hepatotoksik, anti inflamasi, anti mutagenik, dan anti kanker, seperti kanker usus, payudara, paru-paru, dan kulit. $^{3}$

Selain dimanfaatkan untuk minuman dan obat-obatan, kunyit juga merupakan jenis rempah yang biasa digunakan sebagai bumbu masak ${ }^{4}$ sebagai penyedap dan pengurang bau amis pada masakan, juga dioleskan untuk menghentikan darah yang keluar karena luka robek. Pemanfaatan kunyit saat ini sudah sangat luas, baik oleh industri minuman, makanan, kosmetik, obat-obatan, maupun tekstil. ${ }^{5}$ Salah satu dusun di Ponorogo yang menyediakan stok kunyit untuk pasar-pasar di Kota Ponorogo dan beberapa perusahaan jamu adalah Dusun Gembes. Dusun Gembes merupakan salah satu dusun yang terletak di Desa Slahung Kecamatan Slahung Kabupaten Ponorogo dengan wilayah terluas. Dusun Gembes terdiri dari 22 RT dan terletak di perbukitan perbatasan Ponorogo-Pacitan. ${ }^{6}$ Wilayah Dusun Gembes bias dipetakan menjadi 3 zona, yakni zona dataran rendah, pertengahan dan dataran tinggi. Kesemua zona tersebut ada dalam mayoritas adalah lahan pertanian dan lahan Perhutani yang dimanfaatkan untuk keseharian warga.

1 Rezki RS, Dwimas A, dan Siswarni MZ, "Ekstraksi Multi Tahap Kurkumin dari Kunyit (Curcuma Domestica Valet) Menggunakan Pelarut Etanol," Jurnal Teknik Kimia USU, 2015.

2 Mulyani S, Harsojuwono BA, dan Puspawati GAKD, "Potensi Minuman Kunyit Asam (Curcuma domestica Val.-Tamarindus indica L.) sebagai Minuman Kaya Antioksidan," Agritech 34, no. 1 (2014): 65-71.

3 Winarti, C dan N. Nurdjanah, "Peluang Tanaman Rempah dan Obat sebagai Sumber Pangan Fungsional” 24, no. 2 (2005): 47-55.

4 Erling Pasaraenga, Jemmy Abidjulua, dan Runtuwenea Max R. J., "Pemanfaatan Rimpang Kunyit (Curcuma domestica Val) dalam Upaya Mempertahankan Mutu Ikan Layang (Decapterus sp)," Jurnal MIP A Unsrat 2, no. 2 (2013): 84-87.

5 W.P. Winarto, Memanfaatkan Bumbu Dapur untuk Mengatasi Aneka Penyakit (Jakarta: AgroMedia Pustaka, 2003).

6 Warni, Wawancara tentang Transek Dusun Gembes, 16 Juli 2019. 


\section{Indonesian Engagement Journal}

Vol. 2 No. 1 Juni 2021

Kunyit merupakan tanaman yang biasa ditemukan di belakang rumah warga Dusun Gembes, selain itu banyak warga dari Dusun Gembes yang menjadi pengepul kunyit baik dari Dusun Gembes, juga dari luar Dusun Gembes. Rata-rata pengepul kunyit ini menjual kunyit dalam bentuk mentahan saja yang digunakan sebagai bumbu dapur. Sehingga laba yang didapat oleh pengepul dan petani sangat minim dan berdampak pada taraf ekonomi penduduk, sehingga mayoritas masuk dalam kategori menengah ke bawah. Hal ini juga yang menjadi salah satu penyebab banyaknya anak-anak muda yang tidak tinggal di Dusun Gembes, karena lebih memilih untuk merantau dan menjadi TKI untuk meningkatkan taraf ekonomi keluarga dan masyarakat.

Pengabdian ini bertujuan untuk memberikan pelatihan dan pembinaan untuk meningkatkan ekonomi masyarakat melalui pembuatan bubuk kunyit siap minum yang memiliki nilai ekonomi lebih tinggi. Dengan penjualan serbuk kunyit siap minum diharapkan para petani dan pengepul mendapatkan laba yang lebih besar, sehingga dapat meningkatkan taraf ekonomi keluarga. Diharapkan pelatihan ini menjadi pintu awal pengembangan jiwa wirausaha masyarakat Dusun Gembes. Sehingga nantinya mampu memasarkan dan menjual produk serbuk kunyit ini di masyarakat desa lain di Kecamatan Ponorogo, di toko, warung, tokojamu, dan lain sebagainya.

\section{METODE}

\section{Tempat dan Waktu}

Pengabdian ini dilaksanakan di Dusun Gembes, Desa Slahung, Kecamatan Slahung Kabupaten Ponorogo. Pengabdian dilaksanakan tanggal 15 Juli sampai 15 Agustus 2019. Pelatihan dilaksanakan 2 kali karena pertimbangan luasnya daerah dan banyaknya peserta yang harus dilatih.

\section{Bahan dan Alat}

Bahan-bahan yang dibutuhkan dalam pembuatan serbuk kunyit siap minum adalah kunyit segar, gula pasir, vanili dan air. Sedangkan alat-alat yang digunakan dalam pemrosesan serbuk kunyit adalah kompor gas, kuali, sotel, sendok, timbangan, gelas ukur, saringan santan, layah, penggiling atau bisa menggunakan parut. Sedangkan untuk presentasi pelatihan yakni dengan Laptop, LCD Proyektor, dan sound. 


\section{Indonesian Engagement Journal}

Vol. 2 No. 1 Juni 2021

\section{Metode Pelaksanaan Kegiatan}

Pengabdian masyarakat ini menggunakan metode penyuluhan interaktid dan demonstrasi. Pengabdian ini dilaksanakan dalam tiga tahap yakni tahap persiapan, pelaksanaan dan evaluasi. Tahap persiapan meliputi persiapan narasumber, penentuan peserta, persiapan tempat, peralatan, bahan, dana/pembiayaan pelaksanaan. Tahap pelaksanaan meliputi presentasi dan sosialisai produk kunyit dan pemanfaatan produk, dan dilanjutkan demo pengolahan serbuk kunyit siap seduh. Evaluasi dilakukan untuk melihat efektivitas dan efisiensi dari pengabdian ini untuk selanjutnya diberikan tindak lanjut.

\begin{tabular}{|c|c|c|}
\hline Persiapan & $\begin{array}{c}\text { Pelaksanaan pengolahan } \\
\text { serbuk kunyit menjadi } \\
\text { minuman siap seduh }\end{array}$ & Evaluasi \\
\hline $\begin{array}{l}\text { - meliputi persiapan } \\
\text { narasumber, penentuan } \\
\text { peserta, persiapan tempat, } \\
\text { peralatan, bahan, } \\
\text { dana/pembiayaan } \\
\text { pelaksanaan }\end{array}$ & $\begin{array}{l}\text { - presentasi dan sosialisasi } \\
\text { kunyit dan pemanfaatan } \\
\text { produknya dan kemudian } \\
\text { dilanjutkan demonstrasi }\end{array}$ & $\begin{array}{l}\text { - melihat efektivitas dan } \\
\text { efisiensi dari pengabdian ini } \\
\text { untuk selanjutnya diberikan } \\
\text { tindak lanjut }\end{array}$ \\
\hline
\end{tabular}

Bagan 1.1 Metode Pengabdian

\section{HASIL DAN PEMBAHASAN}

\section{Tahap Persiapan}

Sebelum melaksanakan pelatihan, dilakukan analisis SWOT untuk melihat kekuatan, kelemahan, peluang dan tantangan dari pelatihan yang akan dilakukan. Berikut analisis SWOT yang telah dilakukan:

\begin{tabular}{|l|l|}
\hline \multirow{3}{*}{ Strength } & $\begin{array}{l}\text { Bahan yang digunakan mudah di dapat } \\
\text { Modal yang diperlukan sedikit }\end{array}$ \\
(Kekuatan) & $\begin{array}{l}\text { Alat yang digunakan sederhana mudah dicari } \\
\text { Pengolahan tidak memerlukan waktu yang lama }\end{array}$ \\
& $-\begin{array}{l}\text { Pengolahan tidak memerlukan tenaga yang besar } \\
\text { Weakness }\end{array}$ \\
(Kelemahan) & Produk dapat bertahan cukup lama \\
& $-\begin{array}{l}\text { Belum ada SDM yang mampu mengolah } \\
\text { Jenis produk baru, sehingga perlu pengenalan }\end{array}$ \\
\hline
\end{tabular}




\begin{tabular}{|c|c|}
\hline & - Kurangnya inovasi dalam pengemasan \\
\hline $\begin{array}{l}\text { Opportunity } \\
\text { (Peluang) }\end{array}$ & 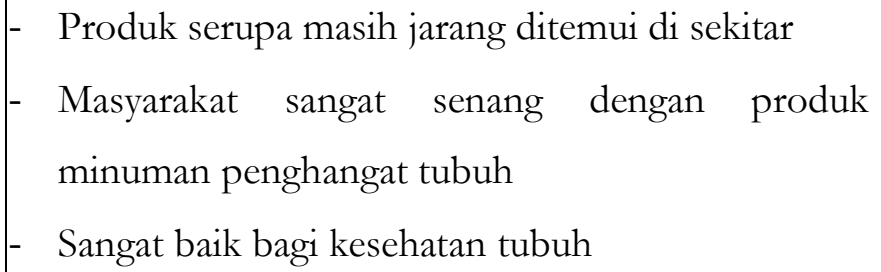 \\
\hline $\begin{array}{l}\text { Threat } \\
\text { (Tantangan) }\end{array}$ & $\begin{array}{l}\text { - Persaingan dengan serbuk minuman penghangat } \\
\text { jenis lainya } \\
\text { - Kreatifitas dan inovasi disetiap perkembangannya }\end{array}$ \\
\hline Output & $\begin{array}{l}\text { Sumber Daya Manusia yang kreatif dan terampil } \\
\text { dalam mengolah usaha } \\
\text { Masyarakat yang produktif dalam kehidupan sehari- } \\
\text { hari }\end{array}$ \\
\hline Aktivitas & $\begin{array}{l}\text { Pelatihan Pemanfaatan Kunyit menjadi Serbuk } \\
\text { MinumanSiapSeduh }\end{array}$ \\
\hline Waktu & $\begin{array}{l}- \text { Senin, 29 Juli } 2019 \text { Pukul } 10.00-13.00 \\
\text { - Sabtu, } 03 \text { Agustus } 2019 \text { Pukul } 18.00-20.30\end{array}$ \\
\hline Pihak yang Terlibat & $\begin{array}{l}\text { - Bapak Seni (Kamituwo) } \\
\text { - Tokoh Masyarakat } \\
\text { - Ibu-ibu RT dan PKK }\end{array}$ \\
\hline Tempat & $\begin{array}{l}\text { - Rumah Bapak Seni (Kamituwo) } \\
\text { - Posko Utama }\end{array}$ \\
\hline
\end{tabular}

Tabel 1.2 Analisis SWOT usaha serbuk kunyit siap seduh

Setelah di awal dilakukanan alisis SWOT di atas, kemudian dilaksanakan tindakan pertama yaitu persiapan. Persiapan yang dilakukan dengan mempertimbangkan hasil analisis SWOT sehingga bias menampung harapan, memaksimalkan peluang dan mengatasi kekurangan dan tantangan. Persiapanpersiapan pelatihan yang dilaksanakan adalah:

a. Persiapan Narasumber

Pertama kali yang dilakukan sebelum menentukan narasumber adalah diskusi dengan seluruh tim. Dari rapat yang dilakukan diperoleh hasil musyawarah dengan mendelegasikan 2 orang dari anggota kelompok untuk mengikuti pelatihan 
pembuatan serbuk kunyit di Kecamatan Kawedanan, Magetan yang telah memiliki usaha yang cukup masyhur. Dari pelatihan tersebut tim melakukan percobaan secara mandiri agar hasil sesuai dengan apa yang diharapkan. Dalam proses percobaan dibutuhkan waktu kurang lebih 2 hari yaitu hari Senin dan Selasa pada tanggal 22 dan 23 Juli 2019. Dalam waktu 2 hari tersebut didapatlah hasil sesuai dengan yang diharapkan, dan dilanjutkan di hari-hari berikutnya untuk berlatih dan mengasah kemampuan agar hasil semakin maksimal. Pelatihan selanjutnya juga memberikan bekal kepada tim yang lain agar nantinya bias memimpin dan mendampingi masingmasing kelompok dalam pelatihan.

b. Penentuan Peserta

Penentuan peserta dilaksanakan dengan penyampaian kepada Bapak Seni selaku Kamituwo terkait program pengabdian. Kemudian diperoleh kesepakatan bahwa peserta adalah ibu-ibu RT dan PKK di seluruh Dusun Gembes. Karena banyaknya RT di Dusun Gembes dan banyaknya peserta akhirnya pelatihan pengolahan dilaksanakan 2 kali.

c. Persiapan Tempat, Peralatan, Bahan dan Pembiayan

Dusun Gembes memiliki wilayah yang sangat luas dengan mencangkup hingga 22 RT. Oleh karena itu, agar pelatihan ini dapat merata mencakup seluruh warga Dusun Gembes, dibuatlah dua kali pelatihan di tempat yang berbeda untuk pelaksanaan pelatihan pembuatan serbuk kunyit.

Dalam pelaksanaan pelatihan kita memerlukan tempat yang luas agar cukup untuk memudahkan proses pembuatan serbuk kunyit bersama ibu-ibu masyarakat Dusun Gembes. Berdasarkan arahan Kepala Dusun dan tokoh masyarakat penyelenggaraan pelatihan pembuatan serbuk kunyit yang pertama di tempat kediaman Kamituwo Gembes, yakni bapak Seni. Sedangkan untuk pelatihan yang kedua bertempat di Rumah Singgah Kepala Desa Slahung di RT. 01 Dsn. Gembes.

Untuk peralatan yang dibutuhkan dalam pelaksanaan Pengabdian adalah Kompor Gas, Kuali, Sotel, Saringan Santan, Layah, Penggiling. Ibu-ibu yang ikut pelatihan dibagi menjadi beberapa kelompok. Masing-masing kelompok didampingi oleh pendamping dari tim untuk memaksimalkan penguasaan dalam pembuatan serbuk kunyit. 


\section{Indonesian Engagement Journal}

Vol. 2 No. 1 Juni 2021

Untuk bahan dalam pembuatan bubuk kunyit menyesuaikan dengan per kilogram bobot kunyit yang akan digunakan. Dan akan berlaku kelipatannya, jika berat kunyit semakin bertambah. Bahan utama dan pembuat bubuk kunyit adalah kunyit $1 \mathrm{~kg}$, gula pasir, vanili, Air.

\section{Tahap Pelaksanaan}

a. Sosialisasi kunyit, pemanfaatannya dan produk turunannya

Sosialisasi ini berisi tentang penjelasan tentang kunyit, manfaatnya dan pengembangan produknya. Diantara manfaat kunyit adalah antioksidan dan anti peradangan, memperlambat penyebaran dan pertumbuhan tumor, memperlancar sistem pencernaan, meringankan gejala rematik, membantu menyembuhkan luka, menyembuhkan penyakit kulit, seperti koreng dan gatal-gatal, dll. Selanjutnya dijelaskan pula bahan yang dibutuhkan dalam pembuatan minuman kunyit bubuk dalam membuat minuman siap seduh. Selain itu juga diterangkan menjadikan minuman kunyit sebagai alternative usaha rumah tangga. Dan kiat-kiat untuk memasarkan produk kunyit olahan siap minum. Termasuk peluang dan tantangan dalam memasarkan produk serbuk kunyit siap seduh.

Pelatihan dilaksanakan dua kali dengan melibatkan peserta ibu-ibu RT dan PKK di seluruh Dusun Gembes. Pelatihan Pertama dilaksanakan di Rumah kediaman Bapak Kepala Dusun. Dilaksanakan pada hari Senin tanggal 29 Juli 2019 pukul 10.00-13.00 WIB. Untuk tahap pertama ini, ibu-ibu yang mengikuti kegiatan sebanyak 20 orang. Ibu-ibu sangat antusias mengikuti pelatihan dengan pendampingan dari tim ini. Sedangkan pelatihan yang kedua bertempat di Posko Utama Kelompok 23 KPM 2019, yang dihadiri oleh ibu-ibu dan pemudi sekitar dengan jumlah kurang lebih 40 orang. Dengan jumlah yang banyak, tidak mengurangi kualitas pelatihan yang diberikan, hanya waktu pelaksaan yang berbeda, yakni dimulai pada pukul 19.00 hingga 20.30 WIB. Pelatihan yang kedua ini dibagi menjadi 5 kelompok besar dengan pendampingan masing-masing kelompok dari tim.

b. Demonstrasi pengolahan Kunyit menjadi Serbuk Minuman Siap Saji

Kegiatan demonstrasi pembuatan minuman serbuk kunyit dilakukan setelah materi selesai disampaikan. Pada kegiatan demonstrasi, narasumber mereview kembali tentang bahan baku sekaligus ukuran baik jumlah maupun berat dari masingmasing bahan baku dari narasumber. Disampaikan pula tahapan proses yang 
dilaksanakan dalam pembuatan minuman serbuk kunyit minuman siap seduh serta alat-alat yang dipakai pada setiap tahap. Narasumber menyampaikan bahwa proses pembuatan minuman serbuk minuman kunyit siap seduh secara umum meliputi 5 tahapan. Tahapan pertama adalah penyiapan bahan, kedua pembuatan ekstrak kunyit, ketiga perebusan, keempat penghalusan serbuk, kelima pengemasan.

Demonstrasi dilakukan oleh narasumber untuk setiap tahap. Tahap pertama adalah persiapan alat dan bahan. Mahasiswa yang ikut membantu sebagai tim menyiapkan alat dan bahan. Tahap kedua adalah pembuatan ekstrak kunyit. Pembuatan ekstrak ini dilakukan dengan memarut kunyit basah, atau bisa juga dengan menggilingnya. Setelah diparut atau bisa juga dihaluskan dengan mesin, kemudian ditambahkan air. Dan kemudian diperas dan disaring dengan saringan atau bisa juga dengan kain.

Gambar 1.1 Proses pembuatan ekstrak kunyit
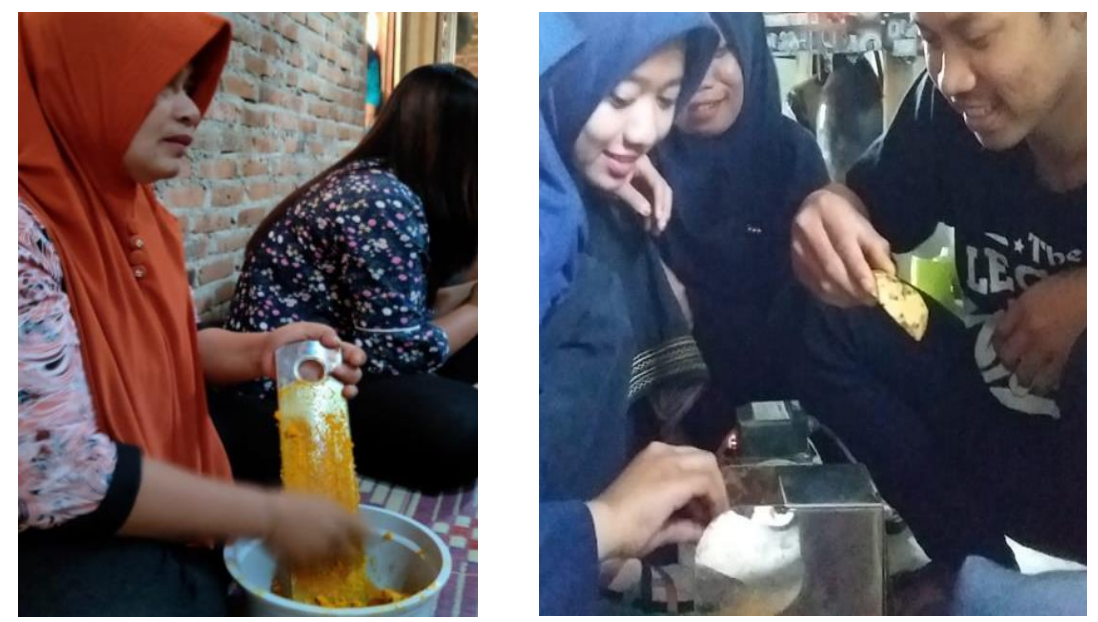

Tahap ketiga perebusan, beberapa peserta mencoba melakukan pemasakan dengan didampingi oleh masing-masing tutor di kelompoknya. Perebusan ini dilakukan sampai air di perebusan habis. Perebusan pada masing-masing kelompok dilakukan secara langsung adalah bertujuan untuk memberikan pengalaman kepada peserta dalam proses pembuatan produk secara langsung, sehingga peserta nantinya diharapkan mampu mempraktekkan secara mandiri pembuatan serbuk kunyit di rumah. 
Gambar 1.2 Proses Perebusan

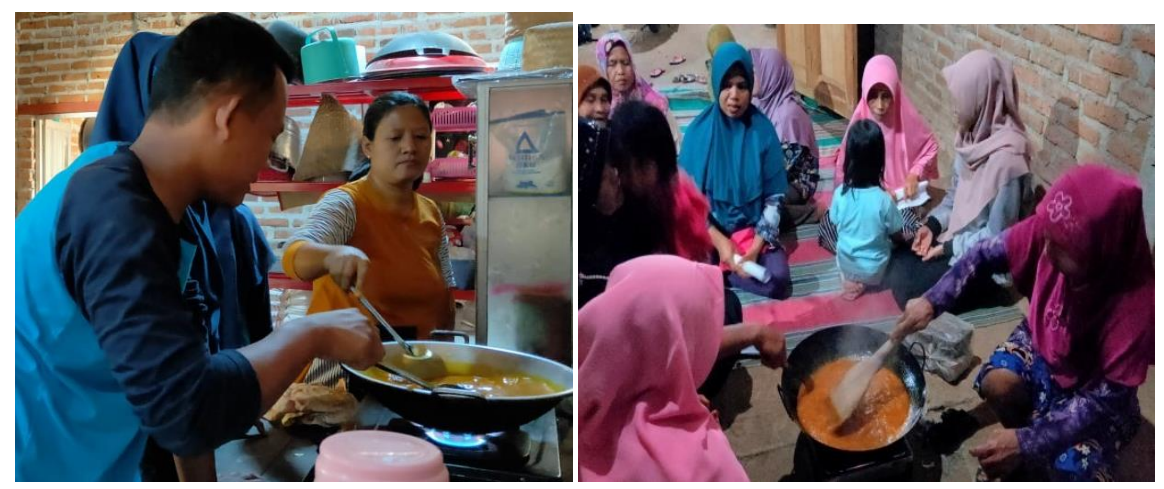

Tahap keempat adalah penghalusan serbuk. Serbuk yang sudah menjadi Kristal itu kemudian ditekan-tekan dengan sendok untuk memisahkan dan menghaluskan bagian-bagian yang masih menggumpal satu dengan yang lain.

Gambar 1.3 Proses Penghalusan

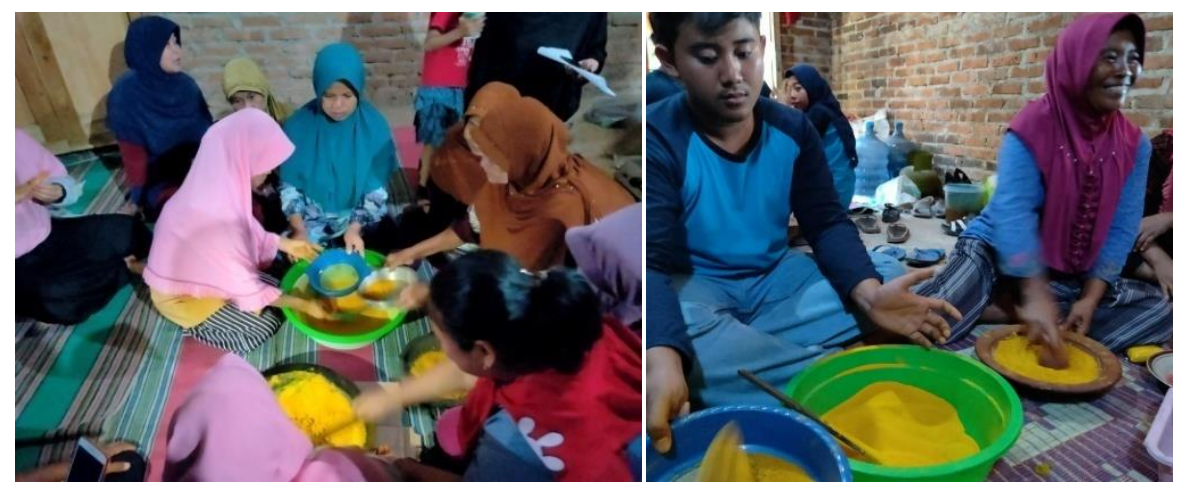

Tahap kelima adalah pengemasan. Serbuk yang sudah jadi dikemas dalam plastik yang sudah disediakan, ada beberapa pilihan wadah yang ditawarkan, yakni 100 gram, 250 gram, hingga 500 gram.

Gambar 1.4 Produk serbuk kunyit dalam kemasan
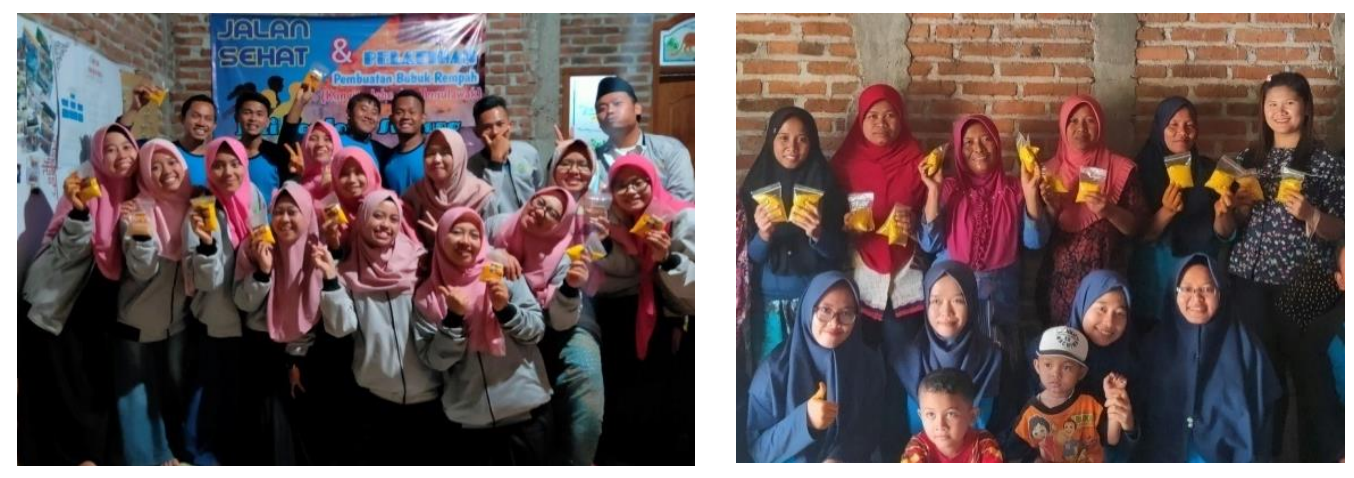


\section{Indonesian Engagement Journal}

Vol. 2 No. 1 Juni 2021

Selama kegiatan berlangsung, seluruh peserta mengikuti kegiatan dengan tekun dan serius. Peserta ikut terlibat dalam setiap tahap dari penyiapan alat dan bahan hingga proses pengemasan selesai. Peserta juga terlihat sangat antusias ketika proses pemasakan telah mencapai tahap akhir, yaitu ketika campuran sari kunyit dan gula mengalami kristalisasi.

\section{Evaluasi}

Tindak lanut setelah dilaksanakannya pelatihan pembuatan atau pengolahan kunyit menjadi bubuk instan siap seduh, maka selanjutnya warga Dusun Gembes dapat mempraktekkan apa yang didapatkan dari pelatihan, dengan dipantau oleh tim mengenai kualitas dan rasanya. Evaluasi bertujuan untuk melakukan penyempurnaan terhadap program yang dilaksanakan apakah sudah sesuai dengan tujuan dan capaian yang diharapkan atau belum. Evaluasi tersebut dilaksakan dengan adanya komunikasi dua arah, untuk menjaring dan memecahkan kendala di dalam melaksanakan sendiri kegiatan maupun terkait hal lain baik yang berkaitan tentang pembuatan maupun pemasaran.

\section{KESIMPULAN}

Kesimpulan yang dapat diambil dari kegiatan pelatihan ini adalah: (1) Kegiatan pelatihan pembuatan kunyit menjadi minuman siap seduh di Dusun Gembes Desa Slahung Kecamatan Slahung Kabupaten Ponorogo dapat meningkatkan pengetahuan sasaran dalam mengolah kunyit menjadi minuman yang layak jual, dan Kegiatan pelatihan dapat mengubah sikap dan keterampilan sasaran dalam memanfaatkan kunyit menjadi produk yang memiliki nilai ekonomi tinggi.

Saran yang dapat diberikan dalam upaya peningkatan pengetahuan dan keterampilan sasaran adalah: (1) Perlu dilakukan kegiatan pengabdian kepada masyarakat secara bertahap dan berkelanjutan kepada sasaran yang sama, sehingga dapat diketahui perkembangan dan perubahan pada pengetahuan, sikap, dan keterampilan sasaran, dan (2) Agar sasaran dari peserta pelatihan dapat mengembangkan hasil pelatihan menjadi sebuah usaha yang menguntungkan secara finansial, maka perlu dilakukan pembinaan lanjutan oleh IAIN Ponorogo dalam hal pengembangan wirausaha bagi sasaran-sasaran kegiatan pengabdian kepada masyarakat yang berminat untuk membangun sebuah wirausaha. 


\section{DAFTAR PUSTAKA}

Mulyani S, Harsojuwono BA, dan Puspawati GAKD. "Potensi Minuman Kunyit Asam (Curcuma domestica Val.-Tamarindus indica L.) sebagai Minuman Kaya Antioksidan." Agritech 34, no. 1 (2014).

Pasaraenga, Erling, Jemmy Abidjulua, dan Runtuwenea Max R. J. "Pemanfaatan Rimpang Kunyit (Curcuma domestica Val) dalam Upaya Mempertahankan Mutu Ikan Layang (Decapterus sp)." Jurnal MIPA Unsrat 2, no. 2 (2013): 8487.

Rezki RS, Dwimas A, dan Siswarni MZ. "Ekstraksi Multi Tahap Kurkumin dari Kunyit (Curcuma Domestica Valet) Menggunakan Pelarut Etanol." Jurnal Teknik Kimia USU, 2015.

Warni. Wawancara tentang Transek Dusun Gembes, 16 Juli 2019.

Winarti, C, dan N. Nurdjanah. "Peluang Tanaman Rempah dan Obat sebagai Sumber Pangan Fungsional" 24, no. 2 (2005).

Winarto, W.P. Memanfaatkan Bumbu Dapur untuk Mengatasi Aneka Penyakit. Jakarta: AgroMedia Pustaka, 2003. 